\title{
Overview of Reproductive Health Consultation and Services
}

\author{
Komal Bajpai ${ }^{1}$, Jasmi Johnson ${ }^{2}$ \\ ${ }^{1}$ M.Sc Nursing $2^{\text {nd }}$ Year Student, Faculty of Nursing, Rama University Kanpur Uttar Pradesh, India \\ ${ }^{2}$ Head of the Department Obs/Gyn Nursing, Faculty of Nursing, Rama University Kanpur Uttar Pradesh, India
}

\begin{abstract}
High order multiple pregnancies have substantial morbidity and mortality. Fertility treatment is commonly responsible for their conception and is available globally with variable regulation. We investigated cross-border fertility treatment in these pregnancies in a UK fetal medicine unit, recording mode of conception, country of fertility treatment, reason for non-UK treatment and fetal reduction. Over an 11-year period, 109 women had a high order multiple pregnancy. Ninety-four women (86\%) conceived with fertility treatment of whom $24(26 \%)$ had this performed overseas. Cross-border fertility treatment poses an increasing challenge to obstetricians. National data on its occurrence is urgently needed ${ }^{1)}$
\end{abstract}

Keywords: CBR, Cross Border Reproductive Care

\section{Background}

Cross border reproductive services refer to individuals crossing national borders to obtain fertility treatment outside their home countries, and to individuals leaving their own countries to facilitate reproduction elsewhere, for instance as gamete donors or surrogate mothers. The reasons for crossing borders vary. Common reasons are the pursuit of personal autonomy motivating avoidance of restrictive laws, such as when a country forbids a reproductive technique, or a particular population group is excluded from access. Other reasons include lack of services in the home country, long waiting lists, better quality of care or less expensive treatment in another country. If health care professionals suggest treatment abroad, they have an obligation to ensure that, like for any other health care referral; they have general knowledge of the safety and quality of care at the site they suggest, for the purpose of facilitating patients' choices. In some countries, it may be illegal to refer for treatment abroad that is deemed illegal in the home country. Because of such constraints on care within countries outlined above, cross border care can overcome limits on patients' autonomy. Health care providers have the responsibility to discuss with their patients what is medically appropriate for the patients to consider, even if that option may not be available locally, to inform patients' decisions and ensure respect for their autonomy. Potential harmful outcomes of cross border reproductive care include medical and legal complications, and negative impacts on health care resources in host and/or patients' own countries. There may not be practical legal recourse for patients who suffer harm and complications from procedures performed abroad. The number of multiple pregnancies may be higher, creating risks for both prospective mothers and their children. Patients may return home without adequate information about their prior treatment, adding substantially to the risks and costs of care. Costs and squeal of complications fall primarily on the patients' home countries' health care systems. Further, cross border care to produce a child of a specific sex, forbidden in the home country, may create or aggravate harmful social effects in some home countries ${ }^{.2)}$

\subsection{The incidence of CBRC}

Comprehensive data on the world wide incidence of CBRC are emerging as researchers, professional organizations, and patient groups delve into the question of who travels to access reproductive care and why. In a 2010 survey of CBRC in Europe, researchers counted 24,000-30,000cycles of cross-border treatment annually, involving 11,000-14,000 patients. Based on a total of 525,640 treatment cycles during the same period, this means that approximately 5\% of all European fertility care involves cross-border travel

\section{Purpose}

Many people travel abroad to access fertility treatments. This growing phenomenon is known as cross border reproductive care (CBRC) or fertility tourism. Due to its complex nature and implications worldwide, CBRC has become an emerging dilemma deserving more attention on the global healthcare agenda ${ }^{3)}$

\section{Methods}

According to the Preferred Reporting Items for Systematic Reviews and Meta-Analyses (PRISMA) guidelines, a systematic review of the literature was performed for all relevant full-text articles published in PubMed in English during the past 18 years to explore $\mathrm{CBRC}$ phenomenon in the new millennium.

\section{The reasons for CBRC}

The factors that motivate patients to travel abroad for fertility care are varied, complex, and often interrelated. The reasons for CBRC fall into four basic categories: 1) access; 2) cost; 3) regulation; and 4) privacy. Each is described briefly below.

Travel to access broader and higher quality care

A patient's ability to access fertility care in his or her country of domicile depends upon the supply of ART services, the quality of care offered, the array of treatment options available, and the wait time associated with obtaining care. Survey data suggest that each of these factors plays a role in motivating cross-border fertility travel, particularly in the 
Middle East, Southeast Asia, and Latin America where ART clinics are sparse

\section{Travel for privacy and cultural comfort}

The physical, psychological, emotional, and financial burdens that infertility can engender lead some patients to seek treatment abroad. Often these patients will patronize a country in which they have extended family or possess a degree of cultural familiarity. A desire for privacy as well as increasingly easy access to international travel is cited by patients as factors in their decision to seek treatment abroad (2). Family connections, cultural comfort, and access to racial and ethnic matched donor gametes also play a role in CBRC

\section{Potential benefits of CBRC}

Fertility travel can potentially benefit patients and their partners, offspring, ART providers, gamete donors and gestational carriers, and local populations in destination countries. Benefits to ART stakeholders flow from the five main factors that motivate cross-border care: improved access, reduced cost, circumvention of legal restrictions or avoidance of discrimination, enhanced revenue streams, and protection of privacy.

\section{Potential harms of CBRC}

The potential harms of CBRC also can be measured according to impact on stakeholders, including patients and their partners, offspring, ART providers, third-party gamete donors and gestational carriers, and local populations in the destination country ${ }^{4)}$

\section{Health and safety concerns}

The gravest concern for traveling patients is the protection of their health and safety. In the ART context, health and safety concerns can focus on the transmission of infectious diseases to patients or genetic disorders to offspring. In the absence of international policies and norms dictating quality control measures, patients are disadvantaged in their ability to discover and assess the standard of care in any given foreign jurisdiction. Essential measures of quality such as the expertise of physicians and embryology staff, the sophistication of the screening, surgical, and laboratory technology, and basic matters to prevent contamination, damage, and misdirection of gametes and embryos can be difficult for a visiting patient to assess. Indeed, patients take some risk when they access any fertility treatment, but the risk increases as patients leave their home country where information about quality is likely more accessible. ${ }^{5)}$

\section{Ethical considerations for departure-country physicians}

Patients who travel for ART begin this journey in their home country, often by consulting several sources for information, including physicians. If a potential ART traveler has a preexisting relationship with a provider in a departure country, several legal and ethical dilemmas can be anticipated. Three specific questions arise:

1) What duty, if any, does the departure-country physician have to inform the patient about opportunities for care abroad?

2) What duty, if any, does a departure-country physician have to inform patients about the risks and benefits of
CBRC including specific risks in a particular destination country?

3) What duty, if any, does a provider have to resume care of a patient who obtains ART services abroad and returns for follow-up care? Guidance for each of these dilemmas can be gleaned from the familiar doctrine of informed consent ${ }^{6}$ )

\section{Duty to inform patients about CBRC opportunities}

A fundamental principle of medical ethics is to respect patients by treating them as autonomous individuals. This means dealing with patients honestly and openly. One prong of the principle of respect for patient autonomy is expressed by the doctrine of informed consent. Briefly, physicians have a duty to provide patients with information necessary to understand their diagnosis and treatment options, as well as the risks and benefits of accepting or foregoing treatment so they can make knowing and informed decisions.

\section{Duty to resume care of a patient who receives CBRC treatment}

A patient who returns from abroad may have little or no documentation explaining the care she received. Lack of medical records can pose significant challenges for treating physicians, raising concerns about whether to treat or resume treatment of returning patients. In some cases, physicians may have a contractual duty to treat returning patients based on pre-existing health insurance or other binding arrangements. Where no such duty exists, physicians are free to accept or decline to accept patients into their practice, so long as any declination is accompanied by reasonable notice giving the patient an opportunity to seek another willing provider. The physician-patient relationship is largely a voluntary one, which both parties may choose to enter or not, so long as their conduct is nondiscriminatory.

\section{Duty to disclose risks and benefits of CBRC care}

Informed consent requires physician disclosure of the risks and benefits of suggested treatment. When a patient asks a departure-country provider about the possibilities of out-ofcountry care, that patient is not inquiring about treatment options being presented by the physician. Thus, the physician does not act as a treating physician visa that patient and has no duty to be informed about or disclose risks and benefits of such treatment. If a physician possesses special knowledge about a particular provider or service of which the patient inquires, a duty arises to not misinform the patient or present false information. A departure-country physician has no independent duty to investigate the risks or benefits of treatment abroad. The physician is free to share opinions about the merits of CBRC and should be clear about whether the information is given as a recommendation or merely as guidance. ${ }^{7)}$

\section{References}

[1] Jaspal R, Prior T, Denton J, Salim R, Banerjee J, Christoph Lees.Eur J Obstet Gynecol Reprod Biol. 2019 Jul;238:63-67. doi: 10.1016/j.ejogrb.2019.04.030. Epub 2019 May 2.PMID: 31112853.

[2] Shenfield F, de Mouson J, Pennings G, Ferraretti AP, Andersen AN, deWert G, et al. Cross border 
reproductive care in six European countries. HumReprod 2010.

[3] De Mouzon J, Nygren K. For the first time, the European IVF Monitoring Group reports on cycles using frozen eggs. ESHRE website. Available at:http://www.eshre.eu/annual_meeting/page.aspx/1361 . Accessed February20,2013.

[4] ESHRE. ESHRE ART Fact Sheet. Available at: http://www.eshre.eu/ESHRE/English/GuidelinesLegal/ART-factsheet/page.aspx/1061.AccessedFebruary20,2013.

[5] Storrow R. Quests for conception: fertility tourists, globalization and feministlegaltheory.HastingsLJ2005, 295-330.

[6] National Center for Transgender Equality, State nondiscrimination laws. Available at: http://www.transequality.org/issues/resources/mapstate-transgender-non-discrimination-laws

[7] Centers for Disease Control \& Prevention. U.S. Department of Health and Human Services, 2013 assisted reproductive technology success rates: national summary report 5(2015). Availableat:http://www.cdc.gov/art/pdf/2013report/art 2013_national_summary_report.pdf. Accessed December4,2015. 